\title{
Observational estimates of detrainment and entrainment in non-precipitating shallow cumulus
}

\author{
M. S. Norgren ${ }^{1}$, J. D. Small ${ }^{2}$, H. H. Jonsson ${ }^{3}$, and P. Y. Chuang ${ }^{4}$ \\ ${ }^{1}$ Dept. of Physics, University of California Santa Cruz, Santa Cruz, CA, USA \\ ${ }^{2}$ Dept. of Meteorology, University of Hawaii at Manoa, Honolulu, HI, USA \\ ${ }^{3}$ Center for Interdisciplinary Remotely-Piloted Aircraft Studies, Naval Postgraduate School, Monterey, CA, USA \\ ${ }^{4}$ Earth and Planetary Sciences, University of California Santa Cruz, Santa Cruz, CA, USA \\ Correspondence to: P. Y. Chuang (pchuang@ucsc.edu)
}

Received: 4 July 2014 - Published in Atmos. Chem. Phys. Discuss.: 26 August 2014

Revised: 27 November 2015 - Accepted: 3 December 2015 - Published: 14 January 2016

\begin{abstract}
Vertical transport associated with cumulus clouds is important to the redistribution of gases, particles, and energy, with subsequent consequences for many aspects of the climate system. Previous studies have suggested that detrainment from clouds can be comparable to the updraft mass flux, and thus represents an important contribution to vertical transport. In this study, we describe a new method to deduce the amounts of gross detrainment and entrainment experienced by non-precipitating cumulus clouds using aircraft observations. The method utilizes equations for three conserved variables: cloud mass, total water, and moist static energy. Optimizing these three equations leads to estimates of the mass fractions of adiabatic mixed-layer air, entrained air and detrained air that the sampled cloud has experienced. The method is applied to six flights of the CIRPAS Twin Otter during the Gulf of Mexico Atmospheric Composition and Climate Study (GoMACCS) which took place in the Houston, Texas region during the summer of 2006 during which 176 small, non-precipitating cumuli were sampled. Using our novel method, we find that, on average, these clouds were comprised of 30 to $70 \%$ mixed-layer air, with entrained air comprising most of the remainder. The mass fraction of detrained air was usually very small, less than $2 \%$, although values larger than $10 \%$ were found in $15 \%$ of clouds. Entrained and detrained air mass fractions both increased with altitude, consistent with some previous observational studies. The largest detrainment events were almost all associated with air that was at their level of neutral buoyancy, which has been hypothesized in previous modeling studies. This new
\end{abstract}

method could be readily used with data from other previous aircraft campaigns to expand our understanding of detrainment for a variety of cloud systems.

\section{Introduction}

One of the important ways cumulus clouds affect the atmosphere is through vertical transport. The redistribution of gases, particles, and energy that originate at or near the Earth's surface to altitudes above the mixed layer is important for a range of phenomena relevant to Earth's atmosphere and climate. For example, the vertical profile of water vapor is critical to longwave heating and cooling profiles, as well as to the subsequent development and evolution of clouds (Malkus, 1954). The long-range transport and atmospheric lifetime of particulates and trace gases are enhanced when they are at higher altitudes due to decreased probability of wet deposition. Aerosol scattering and absorption are also altitude-dependent, in particular their altitude relative to that of any cloud layers (e.g. Liao and Seinfeld, 1998; Chand et al., 2009; Samset and Myhre, 2011). The amount of air that passes through a cloud strongly impacts the degree to which aerosols and gases can be processed via in-cloud liquid-phase reactions. A lack of understanding of the effects of vertical transport is a primary source of uncertainty in climate models (Rougier et al., 2009).

In cumulus clouds, vertical transport can be approximately separated into two modes: (1) the detrainment of cloudy air 
to the surrounding environment during the cloud's active period, i.e., when there is dynamical support for the cloud; and (2) the mixed-layer air that remains after the cloud loses dynamical support and dissipates. While there is some ambiguity in separating these two modes, it is helpful to make this distinction because the first has historically been the subject of greater study, even though the latter can potentially dominate (Wang and Geerts, 2011).

Detrainment is typically used to describe the process by which cloudy air is transferred outside of the cloud volume, i.e., to the surrounding environment (Dawe and Austin, 2011). Detrainment has been divided into two types (de Rooy and Siebesma, 2010). The first is turbulent detrainment and is due to turbulent mixing along the cloud boundary. When cloudy air turbulently mixes with unsaturated environmental air such that the resulting parcel is unsaturated and not completely surrounded by cloud (i.e., is connected to the sub-saturated cloud environment), then the cloudy air has been detrained. A second kind of detrainment has been termed dynamical detrainment (or cloud outflow) because it is driven by organized circulations comparable to the length scale of the cloud rather than smaller turbulent eddies. Such detrainment has been related to buoyancy gradient profiles that cause deceleration and flow divergence (Bretherton and Smolarkiewicz, 1989; de Rooy and Siebesma, 2010), and also to the flow structure of a shedding thermal (Taylor and Baker, 1991; Blyth, 1993; Zhao and Austin, 2005; Blyth et al., 2005).

There is not an extensive history of observational studies of detrainment in clouds (Wang and Geerts, 2011; see also a recent review by de Rooy et al., 2013), and the various methods and cloud types from these studies have yielded a range of views on the process. Some observational estimates come from mass budget studies where, using aircraft flying closed circuits around individual cumuli $(\mathrm{Cu})$, mass and moisture budgets are inferred, from which entrainment and detrainment rates at different levels of the cloud are deduced (Raymond and Wilkening, 1982, 1985; Raga et al., 1990; Raymond et al., 1991; Barnes et al., 1996). These studies typically find that the net detrainment mass flux (defined as the difference between the gross detrainment and entrainment mass fluxes) can be comparable in magnitude to the updraft mass flux, albeit with strong variability with height and in time. One important mechanism of detrainment deduced from these studies is a detraining outflow in collapsing turrets, where air sinks until reaching its level of neutral buoyancy and then diverges outwards from the cloud, causing detrainment to occur only at specific altitudes. Using aircraft observations of summertime cumuli off of Hawaii (with typical cloud depths of $\sim 2 \mathrm{~km}$ ), Raga et al. (1990) found that net detrainment occurred only in the top one-third of the cloud, with the lower parts exhibiting net entrainment. Raymond et al. (1991) combined aircraft and radar observations of summertime thunderstorm clouds over New Mexico (cloud depths ranging between 6 and $12 \mathrm{~km}$ ) and found a similar vertical pattern of detrainment predominantly in the upper portion of clouds. Barnes et al. (1996) studied summertime cumulus and cumulus congestus (cloud depths up to $4 \mathrm{~km}$ ) near coastal Florida, USA, using two coordinated aircraft flying at different altitudes. They found that detrainment varied greatly with time, with the same layer changing from net entrainment to net detrainment, or vice versa, on the order of a few minutes. Perry and Hobbs (1996) found evidence for regions of enhanced humidity "halos" in shallow maritime cumulus (typical cloud depths between 0.5 and $2.5 \mathrm{~km}$ ) off the coast of northeast continental USA, particularly on the downshear side. These regions exhibiting enhanced humidities were typically 1 to 2 cloud radii in length, and increased in size with cloud age. This result is suggestive of active detrainment in cumulus clouds, although the results do not rule out the possibility that these halos are remnants of previous clouds. In contrast, Wang and Geerts (2011) studied orographic cumulus mediocris in Arizona, USA (typical cloud depth of $2 \mathrm{~km}$ ) and found no evidence for continuous detrainment; their measurements downwind of a cloud field are instead consistent with vertical transport dominated by evaporation of the clouds themselves rather than active detrainment by the clouds. We note that these studies are performed in different environments (e.g., clear air relative humidity) with varying cumulus cloud sizes, and thus the results are not necessarily expected to be consistent with each other.

One assumption that mass budget-based studies makes is that the accumulation term is negligible, i.e., the cloud is at steady state with respect to mass. However, Carpenter et al. (1998a) find that the accumulation term can be dominant which implies a potentially large source of uncertainty for the inferred detrainment rates in some observational studies. Another limitation is that these mass budget studies only yield net entrainment or detrainment; these values are not necessarily reflective of gross entrainment and detrainment rates which could be much higher than the net value. For example, there could be no net detrainment (mass loss) from a cloud if it is exactly balanced elsewhere by an equal amount of entrainment. Gross detrainment values are, however, of greater relevance for understanding vertical transport.

Entrainment, in comparison to detrainment, is a much more familiar topic in the cloud physics literature and thus we only highlight a few studies out of many. Entrainment can be defined as the incorporation of air originating outside the cloud volume into the cloud, thus increasing total cloud mass and volume. It is one of the key processes governing the microphysical structure and macrophysical properties of a cloud, and along with precipitation, is responsible for the depletion of cloud water mixing ratio and thus is relevant to cloud lifetime. Entrainment, as with detrainment, can be similarly divided into turbulent and dynamical forms (Houghton and Cramer, 1951), and evidence exists supporting the importance of both processes. Entrainment associated with organized flow has been described using observations 
(e.g. Stith, 1992; Damiani and Vali, 2007) and models (e.g. Zhao and Austin, 2005; Blyth et al., 2005). Through analysis of aircraft observations, Wang et al. (2009) show that the outermost $10 \%$ of cumulus clouds, i.e., cloud edges, are on average strongly depleted in liquid water relative to the interior of the cloud, supporting the idea that turbulent entrainment occurs along the outer surface of the cloud, but not ruling out the possibility of localized entrainment that is then transported to other regions by, e.g., the descending outer shell.

In this study, we will use a novel approach to estimate total gross detrainment and entrainment that has occurred in shallow, non-precipitating cumulus clouds. This method is not able to inform the mechanism for detrainment and entrainment (e.g., cloud-scale dynamical features versus small-scale turbulence), and instead focuses on quantifying the amount of each as a function of height.

\section{Method}

\subsection{Aircraft data}

Data gathered during August and September 2006 as part of the Gulf of Mexico Atmospheric Composition and Climate Study (GoMACCS) are used in this study. The GoMACCS field campaign included 22 research flights carried out by the Twin Otter aircraft (Lu et al., 2008) operated by the Center for Interdisciplinary Remotely-Piloted Aircraft Studies (CIRPAS). The flights were conducted over land in a region outside of Houston, Texas. Of 22 total flight days, data from 6 days $(1,2,8,11,14,15$ September) are analyzed in this study. These 6 days are selected due to a sufficient number of randomly sampled clouds, and all relevant instrumentation functioned properly during the flights. The sampled clouds are small, warm, non-precipitating continental $\mathrm{Cu}$ that typically first form in the late-morning due to surface heating. Sampled cloud sizes are typically 1 to $2 \mathrm{~km}$ in width and depth (see Table 1). Later in the afternoon, deeper convection can be triggered but these events were avoided during these flights. Because of the proximity of the flights to a very large city (Houston, TX) and the many industrial activities in the region, aerosol concentrations are high (accumulation mode aerosol concentrations ranging from 400 to $1600 \mathrm{~cm}^{-3}$ ) and contribute to the lack of precipitation from these clouds. More information about the conditions encountered during these flights can be found in Lu et al. (2008).

The clouds are sampled in random fashion during a series of constant altitude legs, each about $10 \mathrm{~min}$ in duration. This is done by flying the Twin Otter through approximately the center of the nearest appropriate cloud as judged visually by the pilots, with factors such as aircraft turn capabilities, and cloud size and appearance being considered. Of course, clouds are irregularly shaped so exactly where the pilot chooses to penetrate each cloud is not easily defined. This introduces uncertainty in our analysis (as discussed in

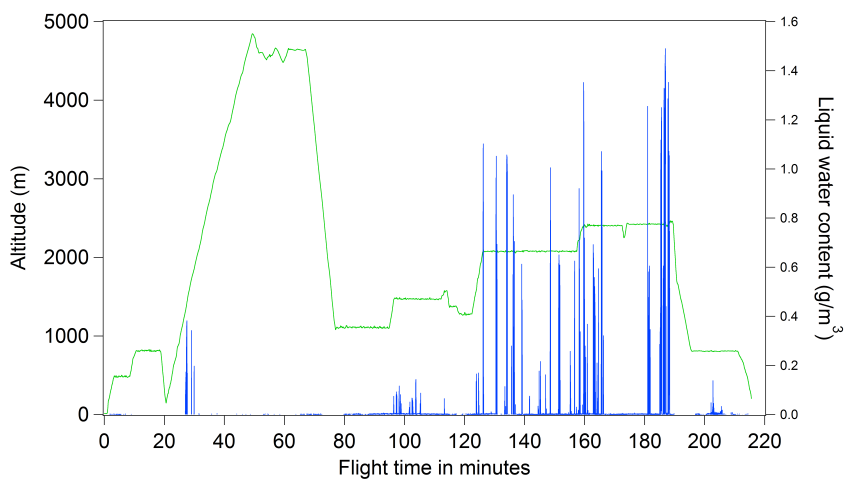

Figure 1. Aircraft altitude and cloud liquid water content as a function of time for the 8 September flight. There were 27 clouds sampled on this day. The clear air sounding occurs from approximately minute 20 to 50 .

more detail in Sect. 2.4 below). Figure 1 shows the altitude profile for the 8 September flight, which is representative of all flight days. A number of level legs can be seen in the altitude profile. For each flight, between 3 and 5 of these correspond to the cloud layer and therefore include a number of cloud penetrations. Note that because of this statistical sampling strategy, no effort is specifically made to sample a cloud more than once. Also of note is the continuous ascent from below cloud base, $\sim 300 \mathrm{~m}$, to above cloud top, $\sim 4800 \mathrm{~m}$, which is utilized in the analysis as our clear-air sounding and which we assume is representative of clear air in the vicinity of all our sampled clouds over the course of the sampling period. Variation of this sounding, either in space or over time, can cause uncertainties in our analysis. Typical aircraft speed is $55 \mathrm{~m} \mathrm{~s}^{-1}$, and we primarily employ $10 \mathrm{~Hz}$ (or $5.5 \mathrm{~m}$ ) data sets.

In situ measurements of temperature, specific humidity $\left(q_{\mathrm{v}}\right)$, and liquid water content (LWC) are needed for our analysis. Temperature was measured using a Rosemount 102E4AL sensor with $0.4^{\circ} \mathrm{C}$ accuracy. In clear air, specific humidity is derived from $1 \mathrm{~Hz}$ dew point temperature measurements made by a chilled mirror dew point hydrometer with Edgetech Dewpointer 137-C3 with $0.2^{\circ} \mathrm{C}$ accuracy. Incloud specific humidity values are assumed to be saturated at the measured temperature. Clouds are identified using a minimum LWC threshold of $0.05 \mathrm{~g} \mathrm{~kg}^{-1}$, as measured by a Gerber particle volume monitor 100A instrument (Gerber et al., 1994). Total specific water $\left(q_{\mathrm{t}}\right)$ is the sum of $q_{\mathrm{v}}$ and LWC (none of the sampled clouds was cold enough for ice to form). Cloud penetrations with LWC satisfying the threshold requirements for a minimum of $6 \mathrm{~s}$, which corresponds to an approximate cloud sample length of $330 \mathrm{~m}$, are identified as clouds and used for this study. The minimum cloud size requirement is imposed so that the clouds used in the study contain enough data points to conduct analyses with reasonable statistics. Figure 1 shows the LWC profile for the flight on 8 September. On this day, 27 clouds were sampled across 
Table 1. Summary of clouds sampled on each flight day. Local time is UTC minus $5 \mathrm{~h}$ (central daylight time).

\begin{tabular}{cccccc}
\hline Date & $\begin{array}{c}\text { Number of } \\
\text { clouds }\end{array}$ & $\begin{array}{c}\text { Avg penetration } \\
\text { length }\end{array}$ & $\begin{array}{c}\text { Takeoff } \\
\text { time [UTC] }\end{array}$ & $\begin{array}{c}\text { Cloud } \\
\text { base [m] }\end{array}$ & $\begin{array}{c}\text { Cloud } \\
\text { top [m] }\end{array}$ \\
\hline 1 Sep & 15 & $890 \mathrm{~m}$ & $16: 52$ & 1330 & 2400 \\
2 Sep & 42 & $730 \mathrm{~m}$ & $16: 02$ & 1460 & 2600 \\
8 Sep & 27 & $660 \mathrm{~m}$ & $16: 54$ & 1322 & 2400 \\
11 Sep & 44 & $590 \mathrm{~m}$ & $14: 29$ & 655 & 3100 \\
14 Sep & 27 & $630 \mathrm{~m}$ & $16: 55$ & 969 & 2600 \\
15 Sep & 21 & $630 \mathrm{~m}$ & $15: 59$ & 1068 & 2800 \\
\hline
\end{tabular}

the various levels, with a mean cloud penetration length of $660 \mathrm{~m}$. Table 1 gives cloud number and size information for each flight day.

In-cloud wetting of the aircraft temperature probe does not appear to be a significant issue during GoMACCS (Small et al., 2009). Further analysis was done for this study to confirm this result. We see no statistically significant bias in clear-air temperature prior to entering a cloud and after leaving the same clouds as would be expected for a wetted temperature probe; $\Delta T=T_{\text {exit }}-T_{\text {entry }}$ has values of $0.18,0.20$ and $0.20 \mathrm{~K}$ when comparing the 1,3 , and $5 \mathrm{~s}$ intervals prior to cloud entry and after departure from the same cloud, which are smaller than the $1 \sigma$ values of $\Delta T$ of $0.35,0.35$, and $0.34 \mathrm{~K}$, respectively. The biases are also smaller than the probe accuracy of $0.4 \mathrm{~K}$. Wetting of the Rosemount probe has been found to result from impaction of drops on the probe housing, which leads to liquid water build up and eventually drops spraying in random directions, some of which reach the probe sensor (Lawson and Cooper, 1998). Wetting biases have been found to depend on cloud LWC and aircraft speed. In the case of GoMACCS, cloud LWC is generally below $0.8 \mathrm{~g} \mathrm{~m}^{-3}$, from which a typical bias of $0.4 \mathrm{~K}$ would be deduced based on clouds sampled by Lawson and Cooper (1998). However, in this study the aircraft speed is about half of that from Lawson and Cooper (1998), which will reduce drop impaction to the probe housing. Impaction also depends on drop size, and during GoMACCS drops are small due to the large aerosol concentrations, with typical sizes much less than $20 \mu \mathrm{m}$ (Small et al., 2009). Lastly, wetting also depends on the cloud width. GoMACCS clouds exhibit widths between 1 and $2 \mathrm{~km}$, which are on the small side for cumuli. We attribute the lack of any statistically significant wetting of the Rosemount during GoMACCS to the combination of all of these factors.

\subsection{Adiabatic clouds}

In order to develop a model of gross entrainment and detrainment, we first explore their effects on an idealized adiabatic cloud. If a parcel of air rises adiabatically, by definition it will exchange neither mass nor energy with the environment. Thus, the mass and energy of the air parcel will be conserved. This also implies that the moist static energy (or MSE) of the parcel also is conserved.
Entrainment and/or detrainment, precipitation, and radiation are the primary processes which can cause cloudy air parcels to deviate from adiabaticity. Entrainment increases the total mass of the cloud while decreasing mean $q_{\mathrm{t}}$ and MSE. This occurs because, relative to clear air at the same altitude, cloudy air is generally warmer (because it is positively buoyant) and moister (because it is cloudy) (e.g. Wang et al., 2009), although the former may not always be true during the cumulus dissipation stage. For a cloud experiencing detrainment, the total mass of the cloud decreases. In our analysis, we assume that the properties of the detrained air are a function of the cloudy air and adiabatic air properties, which tends to cause the cloud MSE and $q_{\mathrm{t}}$ to either stay constant or decrease (depending on the exact set of assumptions; see Sect. 2.4 below for more details). However, the potential decrease in MSE and $q_{\mathrm{t}}$ differs for the same amount of entrained or detrained air, which allows the analysis to distinguish between the two processes.

Precipitation could affect cloud properties, but the focus of this study is on non-precipitating clouds, so this is not an important consideration. The clouds sampled did not precipitate due to the combination of polluted aerosol conditions from the Houston region and the limited depth of the clouds which limits cloud liquid water path (Small et al., 2009).

Net emitted radiation from a cloud causes cooling and therefore decreases MSE, while net absorption warms. During the daytime (when the research flights took place), the net radiative balance for each cloud is determined by the difference between longwave cooling and shortwave heating, which tend to be similar in magnitude. We will assume no net change due to radiation. The bias in cloud temperature, and hence MSE, caused by this assumption is likely to be very small. If we assume a $20 \mathrm{~W} \mathrm{~m}^{-2}$ imbalance, and a mean cloud lifetime of $30 \mathrm{~min}$, the mean temperature change for a $1 \mathrm{~km}$ deep cloud will be a few hundredths of a Kelvin and thus unlikely to be a large source of uncertainty in this analysis.

In the absence of substantial effects by precipitation and radiation, we are left with only entrainment and detrainment as the processes capable of altering clouds mass, MSE and $q_{\mathrm{t}}$ from the initial adiabatic values. 


\subsection{Conserved variables}

Our analysis of detrainment and entrainment in cumulus clouds is based on the conservation of three variables: mass, $q_{\mathrm{t}}$, and moist static energy. The total mass of a cloud, $M_{\mathrm{c}}$, is the sum of all gases, liquids, and solids contained within the volume of the cloud. The total specific water of a cloud parcel $\left(q_{\mathrm{t}}\right)$ is the sum of the liquid water and the water vapor, given by

$q_{\mathrm{t}}=q_{\mathrm{v}}+q_{\mathrm{l}}$,

where $q_{\mathrm{v}}$ is the specific humidity and $q_{1}$ is the specific liquid water, both in units of $\mathrm{g} \mathrm{kg}^{-1}$. Again, these clouds are warm, so Eq. (1) excludes ice. Total water is conserved for an adiabatic process because there is no mass exchange with the environment, and therefore $q_{\mathrm{t}}$ is constant.

Moist static energy $s$ is a measure of an air parcel's energy in units $\mathrm{J} \mathrm{kg}^{-1}$ and to good approximation is conserved during adiabatic ascent and/or descent:

$s=c_{p} T+g h+q_{\mathrm{v}} L_{\mathrm{v}}$,

where $T$ is absolute temperature, the heat capacity of moist air $c_{p}=c_{p}\left(q_{\mathrm{v}}\right)=c_{p \mathrm{~d}}\left(1+0.9 q_{\mathrm{v}}\right)$ where $c_{p \mathrm{~d}}$ is the heat capacity of dry air (assumed to be a constant value $\left.1005 \mathrm{~J} \mathrm{~kg}^{-1} \mathrm{~K}^{-1}\right), g$ is the gravitational acceleration, $h$ is the height of the air parcel above sea level, $q_{\mathrm{v}}$ is the specific humidity, and $L_{\mathrm{v}}=2260 \mathrm{~kJ} \mathrm{~kg}^{-1}$ is the latent heat of vaporization of water (we ignore the effects of temperature on $L_{\mathrm{v}}$ because they are small). Typical uncertainties in calculated $s$ are a few tenths of a percent based on instrumental uncertainties.

As a cloud parcel is lifted along the dry adiabat, the increase in potential energy is accompanied by a decrease in the sensible heat term; the parcel cools as it increases in height. If the parcel is saturated and liquid water is present, the decrease in $q_{\mathrm{v}}$ due to condensation is offset by the release of latent heat, increasing the parcel temperature. We have argued above (Sect. 2.2) that processes such as precipitation and net radiation flux divergence that can cause MSE to not be conserved are likely negligible in this study.

\subsection{Conservation equations}

For the clouds chosen in this analysis, we assume that each cloud has a mass that is determined by the balance of three terms (see Fig. 2 for a schematic): (a) air that has been adiabatically lifted from near the surface; (b) air that has entrained into the cloud; and (c) air that has detrained from the cloud. Starting with this simple model, we make two important assumptions in order to proceed with the analysis:

1. Entrainment occurs perfectly laterally, so that all the entrained air in the cloud at the aircraft sampling altitude originates from clear air at the same altitude. A recent

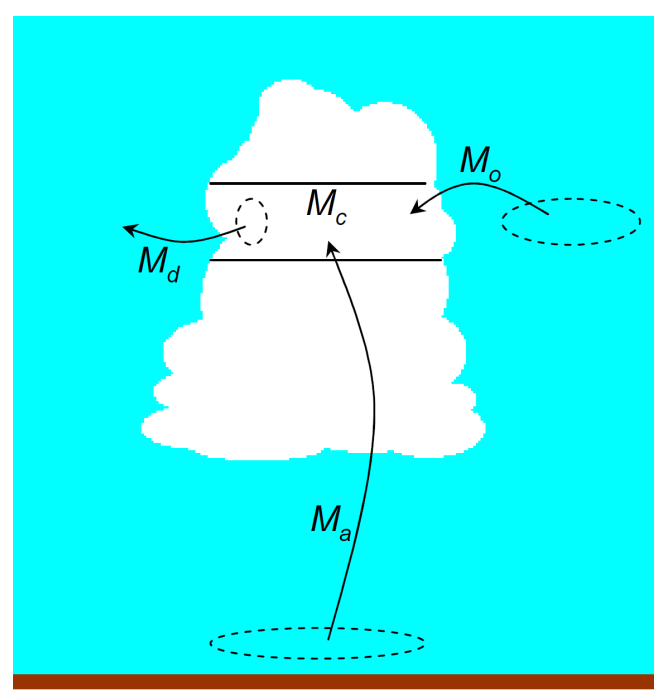

Figure 2. A sketch showing the sources of air that are assumed in this analysis to comprise a cloud. $M_{\mathrm{a}}$ rises adiabatically from cloud base, $M_{\mathrm{O}}$ is entrained laterally at the altitude the cloud is sampled, and $M_{\mathrm{d}}$ is detrained air.

review paper (de Rooy et al., 2013) argues that "lateral entrainment is the dominant mixing mechanism in comparison with the cloud-top entrainment in shallow cumulus convection", an idea with a long history (see references and discussion in de Rooy et al., 2013) supported by recent LES-based studies (Heus et al., 2008; Yeo and Romps, 2013). We will test the sensitivity of our results to this assumption.

2. Two end-member scenarios for detrainment are (a) that detrainment occurred exactly at the same time as the aircraft penetration of the cloud, i.e., detrainment happened at the last possible moment; and (b) that detrainment occurred when the cloud properties were nearly adiabatic (before substantial entrainment has occurred) i.e., detrainment happened very early during cloud formation. The corresponding properties of the detrained air for these end-members would be (a) detrained air has the identical properties as the cloud at the sampled level and (b) detrained air has the identical properties as the adiabatic mixed layer air. In this analysis, we assume that the detrained air has properties represented by the mean of these two end-members, which is intended to represent a middle scenario. We will again test the sensitivity of our results to this assumption.

With these assumptions, we can now write conservation equations describing our system. We apply our analysis to each cloud penetration because, as previously stated, each cloud is only sampled once. Thus, the analysis results apply only to each cloud at the level of aircraft sampling, as illustrated in Fig. 2, and not to the entire cloud. By mass conservation, the mass of the thin cloud slice $M_{\mathrm{c}}$ can be given 
by

$M_{\mathrm{a}}+M_{\mathrm{o}}-M_{\mathrm{d}}=M_{\mathrm{c}}$,

where the subscript a is mixed-layer air risen adiabatically, o is laterally entrained air (air originating outside the cloud), $d$ is laterally detrained air, and $\mathrm{c}$ is aircraft-sampled cloudy air. Dividing Eq. (3) by $M_{\mathrm{c}}$, we obtain

$m_{\mathrm{a}}+m_{\mathrm{o}}-m_{\mathrm{d}}=1$,

where we have now written the equation in terms of mass fractions $m_{\mathrm{a}}=M_{\mathrm{a}} / M_{\mathrm{c}}, m_{\mathrm{o}}=\mathrm{o} / M_{\mathrm{c}}$, and $m_{\mathrm{d}}=M_{\mathrm{d}} / M_{\mathrm{c}}$. Working with mass fractions is more convenient and useful for the purpose of comparing results among different clouds because the results do not explicitly depend on the cloud mass. Furthermore, given our cloud sampling method, we would need to make assumptions about cloud shape in order to determine $M_{\mathrm{c}}$, introducing more sources of error.

We note that in Sect. 2.2, detrainment was defined as an active process of turbulence or organized circulations removing air from a cloud. By defining the conservation of mass as we do in Eq. (4), any air that is within the cloud but then later becomes external to the cloud is considered detrained air. Thus, detrainment as defined by this analysis can occur either actively, where cloudy air is transferred outside the cloud via organized flow or turbulence, or passively, where enough air is entrained into the cloud to lower the LWC below our cloud threshold LWC. The latter would not normally be considered detrainment but rather cloud dissipation, but it is relevant to vertical mass transport as described in the Introduction.

We can also construct a conservation equation for the moist static energy of our sampled cloud:

$s_{\mathrm{a}} M_{\mathrm{a}}+s_{\mathrm{o}} M_{\mathrm{o}}-s_{\mathrm{d}} M_{\mathrm{d}}=s_{\mathrm{c}} M_{\mathrm{c}}$,

where s is MSE and the same subscripts from Eq. (3) apply. The adiabatic air MSE, $s_{\mathrm{a}}$, is computed from the lowest (by altitude) 200 data points on each given flight day. These points are all in the surface mixed layer, which is generally well-mixed because all flights occurred around the middle of the day when the continental convective boundary layer exhibits strong turbulence. The MSE of entrained air $s_{\mathrm{O}}$ is taken from the clear air sounding acquired during each flight. Due to our assumption of lateral entrainment, $s_{\mathrm{O}}$ is taken to be the MSE value of the clear air at the altitude of the cloud penetration. The MSE of the cloud slice $s_{\mathrm{c}}$ is determined as the mean MSE derived from the aircraft observations for each cloud penetration. By assumption \#2 above, the MSE of the air that detrains is $s_{\mathrm{d}}=\left(s_{\mathrm{a}}+s_{\mathrm{c}}\right) / 2$. Again dividing by $M_{\mathrm{c}}$ to write in terms of mass fractions:

$s_{\mathrm{a}} m_{\mathrm{a}}+s_{\mathrm{o}} m_{\mathrm{o}}-s_{\mathrm{d}} m_{\mathrm{d}}=s_{\mathrm{c}}$

Equation (6) thus contains the same unknowns, $m_{\mathrm{a}}, m_{\mathrm{o}}$, and $m_{\mathrm{d}}$, as Eq. (4), but with MSE coefficients that are determined from aircraft measurements. A third equation based on conservation of total specific water can also be derived in the same way as for MSE:

$q_{\mathrm{a}} m_{\mathrm{a}}+q_{\mathrm{o}} m_{\mathrm{o}}-q_{\mathrm{d}} m_{\mathrm{d}}=q_{\mathrm{c}}$

The conservation equations are re-written as a set of nonlinear equations in order to restrict the mass fractions to positive, physically plausible solutions:

$x^{2}+y^{2}-z^{2}-1=0$

$c_{1} x^{2}+c_{2} y^{2}-c_{3} z^{2}-1=0$

$d_{1} x^{2}+d_{2} y^{2}-d_{3} z^{2}-1=0$,

where $x^{2}=m_{\mathrm{a}}, y^{2}=m_{\mathrm{o}}$, and $z^{2}=m_{\mathrm{d}}$ are the three unknowns, while the coefficients are computed from aircraft observations as $c_{1}=s_{\mathrm{a}} / s_{\mathrm{c}}, c_{2}=s_{\mathrm{o}} / s_{\mathrm{c}}, c_{3}=s_{\mathrm{d}} / s_{\mathrm{c}}$, and $d_{1}=$ $q_{\mathrm{a}} / q_{\mathrm{c}}, d_{2}=q_{\mathrm{o}} / q_{\mathrm{c}}, d_{3}=q_{\mathrm{d}} / q_{\mathrm{c}}$. To solve for the three unknowns $m_{\mathrm{a}}, m_{\mathrm{o}}$, and $m_{\mathrm{d}}$, we perform the following:

a. For each cloud penetration, we use in-cloud observations to compute the mean moist static energy $s_{\mathrm{c}}$ and mean total specific water $q_{\mathrm{c}}$.

b. We use aircraft observations to compute the properties of the end-member air masses, i.e., $s_{\mathrm{a}}$ and $q_{\mathrm{a}}$ (adiabatic mixed-layer air), $s_{\mathrm{o}}$ and $q_{\mathrm{o}}$ (entrained air), and $s_{\mathrm{d}}$ and $q_{\mathrm{d}}$ (detrained air). See the discussion following Eq. (5) for details on how this is done.

c. Using the results from (a) and (b), we can calculate all the coefficients $c_{i}$ and $d_{i}$ in Eqs. (9) and (10), respectively.

d. We use non-linear optimization which minimizes the residuals for the system of Eqs. (8) to (10) to determine a best estimate for $x^{2}=m_{\mathrm{a}}, y^{2}=m_{\mathrm{o}}$ and $z^{2}=m_{\mathrm{d}}$ for each penetration. The magnitude of the total residual is an estimate of the uncertainty in the solution.

This method weights each data point of the cloud penetration equally in calculating mean penetration values of $c_{i}$ and $d_{i}$ in Eqs. (9) and (10). However, this can potentially bias the results because in reality a cloud slice is two-dimensional, whereas the penetration is one-dimensional. If we assume the cloud slice is circular in cross-section, air sampled during the penetration near the cloud edge is representative of a much larger area than air sampled at the cloud center. Our analysis, then, potentially biases the data towards values near the center of the cloud and under-represents data from cloud edges (Hoffmann et al., 2014). However, the aircraft may not always sample the exact center of a cloud, and still assuming clouds are circular in shape, a cloud penetration not through the center of the cloud may possibly over-represent the cloud edge data. To evaluate these potential effects on our analysis, we also solve for $m_{\mathrm{a}}, m_{\mathrm{o}}$, and $m_{\mathrm{d}}$ using only the cloud properties from the first and last second $(\sim 55 \mathrm{~m})$ of the cloud penetration (i.e., in computing $c_{i}$ and $d_{i}$ in Eqs. 9 and 10), which focuses the analysis strictly on air near the cloud edge. 


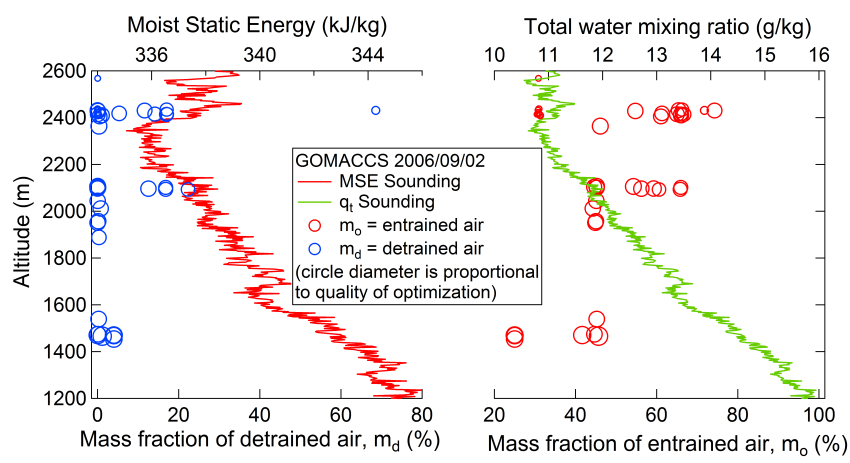

Figure 3. Mass fractions of detrained and entrained air as a function of altitude, along with clear air soundings of MSE and $q_{\mathrm{t}}$, for 2 September 2006. Larger circles indicate smaller optimization residuals, i.e., less uncertainty in estimated $m_{\mathrm{d}}$ and $m_{\mathrm{O}}$.

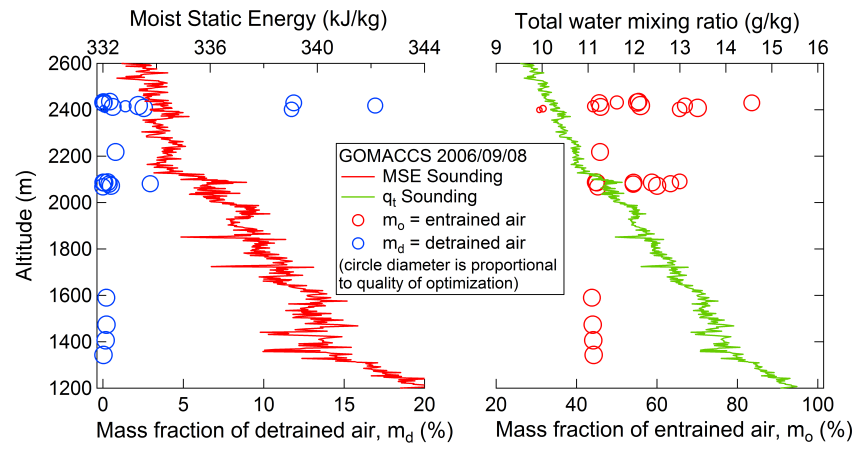

Figure 4. Mass fractions of detrained and entrained air as a function of altitude, along with clear air soundings of MSE and $q_{\mathrm{t}}$, for 8 September 2006. Larger circles indicate smaller optimization residuals, i.e., less uncertainty in estimated $m_{\mathrm{d}}$ and $m_{\mathrm{O}}$.

\section{Results and discussion}

\subsection{Individual flight day results}

Figures 3 and 4 show example results from the optimizations for 2 of the 6 flight days. On each plot, the left panel plots the mass fraction of detrained air $m_{\mathrm{d}}$ (in units of percent), while the right panel plots the mass fraction of entrained air into the cloud, $m_{\mathrm{o}}$, both as a function of altitude, with one point for each cloud penetration. There are a total of 176 penetrations over the 6 days analyzed. The clear-air soundings of MSE and $q_{\mathrm{t}}$ for the flight day are also given on the left and right side, respectively.

The success of the optimization is measured by deviation of the three conservation equations (Eqs. 8 to 10) from zero. The combined total error is calculated as

$\epsilon_{\mathrm{t}}=\sqrt{\epsilon_{M}^{2}+\epsilon_{E}^{2}+\epsilon_{Q}^{2}}$,

where $\epsilon_{\mathrm{t}}$ represents the total root-mean square error associated with the individual residuals from the mass, MSE, and moisture equations ( $\epsilon_{M}, \epsilon_{E}$ and $\epsilon_{Q}$ respectively). The cloud

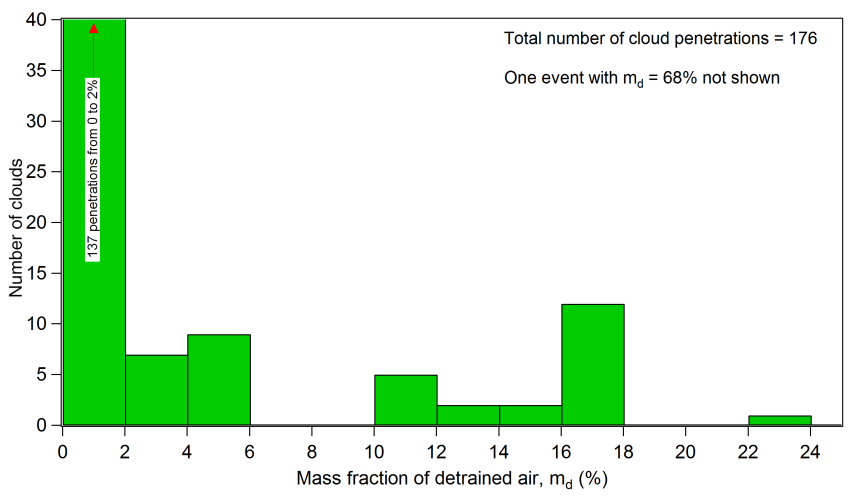

Figure 5. Histogram of detrained air mass fractions for all flight days.

marker sizes in Figs. 3 and 4 for $m_{\mathrm{d}}$ and $m_{\mathrm{o}}$ are inversely proportional to the value of $\epsilon_{\mathrm{t}}$. Therefore, the largest markers correspond to clouds with optimizations that yielded the smallest residuals in Eqs. (8) to (10). Note that these equations are all order unity due to the normalization. For all clouds sampled, $\epsilon_{\mathrm{t}}$ had a median value of 0.07 , a mean value of 0.15 , and a standard deviation of 0.11 .

\subsubsection{Detrained air}

Our analysis indicates that the sampled non-precipitating cumulus clouds exhibit $m_{\mathrm{d}}$ values that are below $2 \%$, although there are a number of cases when some substantially higher $m_{\mathrm{d}}$ values are inferred. Figure 5 shows the distribution of $m_{\mathrm{d}}$ for all flight days (176 clouds). The majority (78\%) of cloud penetrations exhibit $m_{\mathrm{d}}$ values below $2 \%$, while $15 \%$ of clouds have an $m_{\mathrm{d}}$ value above $10 \%$. Only two events exhibit $m_{\mathrm{d}}$ values larger than $18 \%$, and the largest $m_{\mathrm{d}}$ value was $68 \%$. On almost all days (results not all shown), the biggest $m_{\mathrm{d}}$ values are found at the highest sampling altitudes. The one exception is on 11 September when some larger $m_{\mathrm{d}}$ values are found in the middle part of the clouds. Small $(<2 \%)$ $m_{\mathrm{d}}$ values were found at all levels, but made up a larger fraction of the observations at lower portions of the clouds.

To compare the vertical distribution of detrained air among different days, all cloud penetration altitudes are normalized with respect to cloud base and cloud top altitude for each flight day. The clouds are then sorted into five evenly spaced normalized altitude $(\hat{z})$ bins, and for each bin a mean $\hat{z}$ and $m_{\mathrm{d}}$ is computed. All clouds were weighted equally, and the penetration length through each cloud was not factored into the mean $m_{\mathrm{d}}$ calculation. The uncertainty in $\hat{z}$ on a day-byday basis is likely small compared to the $\hat{z}$ bin spacing. Cloud base altitude is easily determined within $\sim 100 \mathrm{~m}$ from in situ measurements. Cloud top altitude is less easily determined by the pilot, but the uncertainty is likely modest compared to the total cloud layer depth as cloud top is usually constrained by a temperature and/or humidity inversion. Figure 6 shows that, in the mean, $m_{\mathrm{d}}$ does tend to increase with altitude, al- 


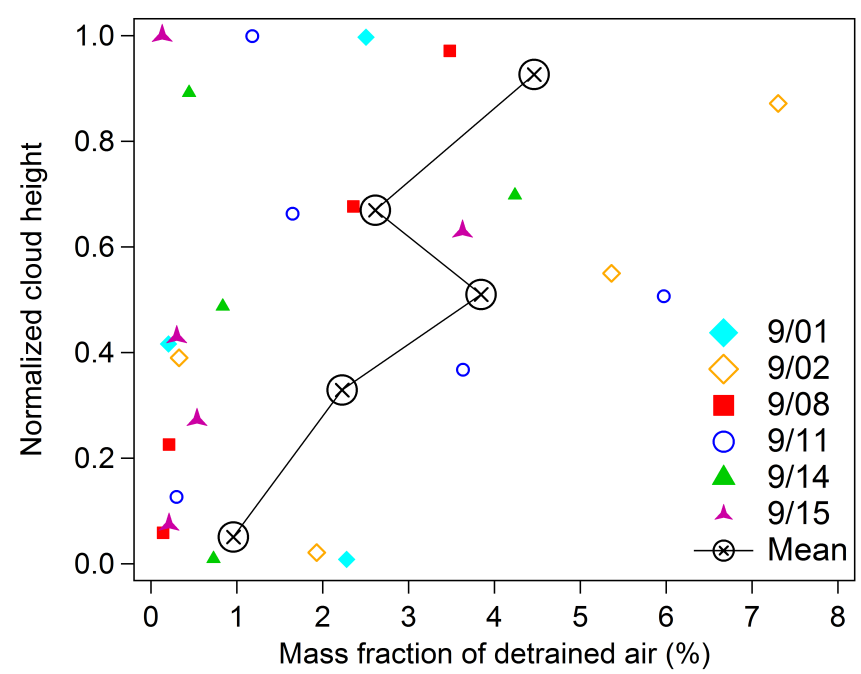

Figure 6. Vertical detrainment mass fraction profile for all flight days. Altitude for each flight day is normalized to an altitude set ranging from cloud base to cloud top.

though the upper portions of the cloud tend to exhibit a lot of variability. The mean values are not large at any altitude, with the smallest value of $1 \%$ closest to cloud base and a maximum in the highest $\hat{z}$ bin of less than $5 \%$, and an overall mean of $3 \%$.

It is noteworthy that few large $m_{\mathrm{d}}$ values are observed, with only one value over $25 \%$. All clouds analyzed here primarily dissipate by evaporation because they are not precipitating. At the end of a cloud's life, we expect $m_{\mathrm{d}}$ to be equal to $m_{\mathrm{c}}$, since at this point the cloud has dissipated. While completely dissipated clouds are not the target for this analysis, we might expect to see some high $m_{\mathrm{d}}$ values associated with clouds near the end of their life cycle. However, high values of $m_{\mathrm{d}}$ were inferred only once in this study. One potential reason is that the pilots may have considered strongly dissipating clouds to be visually unappealing targets. In a cloud field with many choices of cloud targets, such a bias in pilot judgment could bias our statistical sampling. The constraint that clouds must have sample lengths over $330 \mathrm{~m}$ to be considered for analysis may also contribute to limiting $m_{\mathrm{d}}$ values. A dissipating cloud whose diameter shrinks to less than $330 \mathrm{~m}$ will not yet have reached the point where $m_{\mathrm{d}}=m_{\mathrm{c}}$. Alternately, as noted earlier, previous studies (e.g. Carpenter et al., 1998a) have inferred that detrainment occurs at specific levels within clouds. Because we only sampled one level of each cloud, we may not have been sampling at the level that detrainment was occurring.

\subsubsection{Entrained air}

The mass fraction of entrained air within a cloud, $m_{\mathrm{o}}$, typically ranges from 30 to $70 \%$ (illustrated in Figs. 3 and 4). Figure 7 shows the $m_{\mathrm{o}}$ distribution for all flight days. The median $m_{\mathrm{o}}$ is $45 \%$, the mean is $49 \%$, and a standard devi-

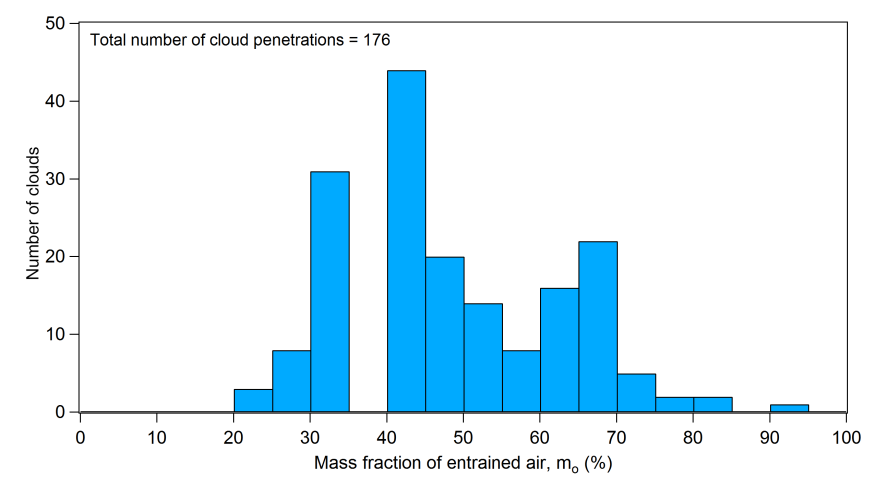

Figure 7. Histogram of entrained air mass fractions for all flight days.

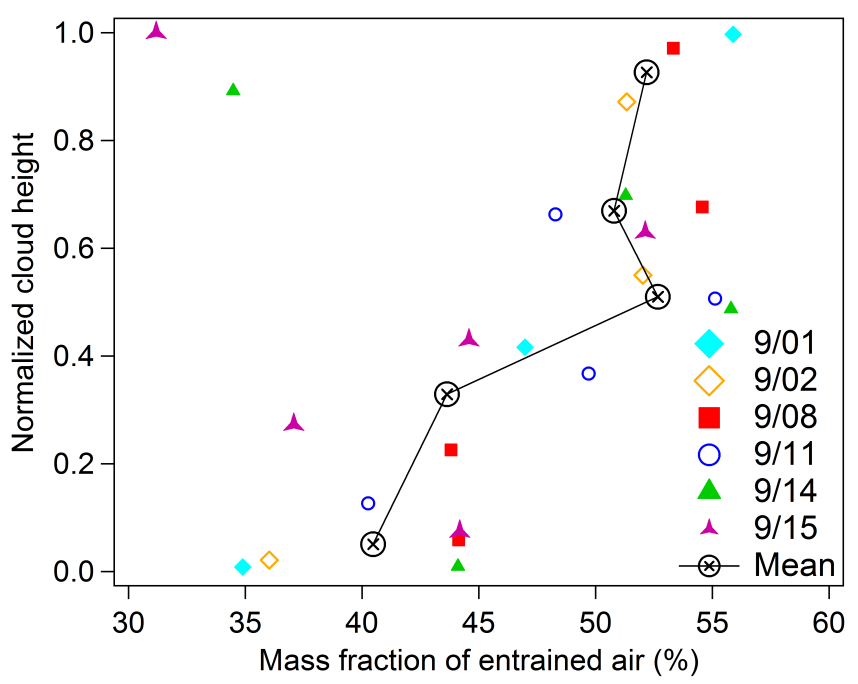

Figure 8. Vertical entrainment mass fraction profile for all flight days. Altitude for each flight day is normalized to an altitude set ranging from cloud base to cloud top.

ation of $14 \%$. The full range is between 20 and $90 \%$. The amount of entrained air is considerably more than the mass of detrained air composing a cloud, and there is only one cloud that exhibits $m_{\mathrm{d}}$ greater than $m_{\mathrm{o}}$.

A vertical profile of $m_{0}$ for each day is created in the same manner as the one for $m_{\mathrm{d}}$ and is shown in Fig. 8. This plot shows that $m_{\mathrm{o}}$ tends to be larger in the upper portion of clouds, with mean values between 50 and $55 \%$ in the upper half of the clouds (normalized altitudes $\hat{z}>0.5$ ), compared to mean values around 40 to $45 \%$ in the lower half of the clouds. As with the detrainment fraction, there is substantial variability at each level.

These results in general seem physically reasonable. The large values of $m_{\mathrm{o}}$ are consistent with Barnes et al. (1996) which showed that the entrainment fluxes can be similar to or larger than the vertical mass fluxes. Relatively large values of $m_{\mathrm{o}}$ can occur within these clouds because the high humidity of the surrounding environmental air in south Texas 
$\left(q_{\mathrm{t}} \sim 10\right.$ to $\left.16 \mathrm{~g} \mathrm{~kg}^{-1}\right)$ in the cloud layer means that the drying effect from entrainment is not as strong as it would be in much drier environments such as New Mexico or Colorado (which have been the setting for numerous previous cumulus studies). In a drier environment, a large entrainment fraction would lead to the complete dissipation of the cloud. The wide range of $m_{\mathrm{o}}$ values is consistent with having sampled clouds at different stages of their life cycle, which one would expect from random aircraft sampling of clouds (even considering the possible bias against strongly dissipating clouds discussed above). The increase in $m_{\mathrm{O}}$ with altitude is consistent with the common observation that the adiabaticity (ratio of the measured cloud LWC to adiabatic LWC) in these clouds decreases with height (e.g., Lu et al., 2008), although drying of the environmental air with altitude may also play a role. Greater entrainment in the upper-portion of the cloud is also consistent with the shedding thermal picture of cumulus growth (e.g. Kitchen and Caughey, 1981; Blyth et al., 2005), where entrained air creates the subsiding shell of cold air at the periphery of the cloud. This air is entrained into the cloud somewhere below cloud top, and is subsequently transported to higher levels in the buoyant updraft.

The overall picture that emerges from our analysis, then, is that the sampled clouds are composed of roughly equal parts entrained air and adiabatic mixed-layer air, and have detrained relatively little of their mass, although a minority $(15 \%)$ exhibit appreciable amounts of detrainment (above $10 \%$ mass fraction). Both entrainment and detrainment mass fractions tend to increase with altitude. We next examine how robust these results are to the assumptions made in the analysis.

\subsection{Sensitivity tests}

\subsubsection{Cloud-edge only}

A straight-line penetration of a cloud can potentially misrepresent the area-averaged cloud properties by biasing the measurements in a number of ways. As described in Sect. 2.4, one such bias is to emphasize the interior of the cloud at the expense of cloud edge. To see how much an effect this has on the optimized parameters, we re-ran the optimizations using data only sampled from the outermost $50 \mathrm{~m}$ at the edge of the cloud. The resulting ranges of $m_{\mathrm{d}}$ and $m_{\mathrm{o}}$ (not shown) are not changed significantly, suggesting that such a bias did not affect our analysis.

\subsubsection{Entrainment source level}

We previously made the assumption that entrainment occurs only laterally at each sampling level. Although this is an oversimplification of the entrainment process, and thus is a limitation of this model, there exists justification for this assumption. As discussed above (Sect. 2.4), support for lateral

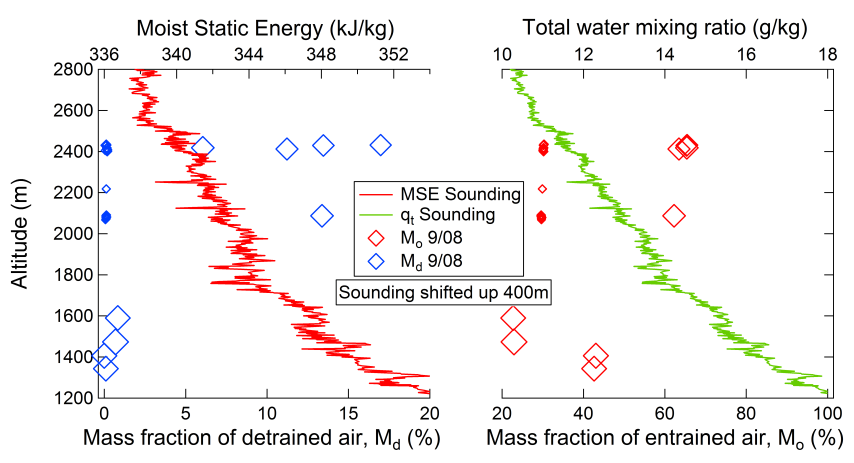

Figure 9. Mass fractions of detrained and entrained air as a function of altitude using shifted clear air soundings of MSE and $q_{\mathrm{t}}$, for 8 September 2006. Large diamonds indicate smaller optimization residuals, i.e., less uncertainty in estimated $m_{\mathrm{d}}$ and $m_{\mathrm{o}}$. The soundings used in this case were shifted upwards by $400 \mathrm{~m}$.

entrainment as the primary mechanism has gained substantial support (de Rooy et al., 2013).

We performed sensitivity tests of our model to the assumed source level of entrained air. In simulations of cumulus congestus with cloud height of $8 \mathrm{~km}$, Yeo and Romps (2013) find that entrained air within the cloud at each height can be traced to air in the environment at an altitude of 1 to $2 \mathrm{~km}$ lower, at least during the mature and dissipating stages. If we assume self-similarity in the vertical direction, then for the clouds in this study (with depths of 1 to $2 \mathrm{~km}$ ), the equivalent entrainment altitude is a few hundred meters below the sampling level. Thus, we test the sensitivity of our results by performing the optimization using MSE and $q_{\mathrm{t}}$ soundings that are shifted upwards or downwards in altitude by $400 \mathrm{~m}$. Since the MSE and $q_{\mathrm{t}}$ soundings, in general, exhibit a decrease with height, this has the effect of changing the MSE and $q_{\mathrm{t}}$ of the source of entrained air.

An example of this sensitivity test is shown in Fig. 9, where the entrainment altitude is shifted upwards by $400 \mathrm{~m}$ for the flight of 8 September (compare these results with Fig. 4). There is some increase in $m_{\mathrm{d}}$ for some of the penetrations, although for others, lower $m_{\mathrm{d}}$ is deduced. The mean $m_{\mathrm{d}}$ is nearly the same, with mean and $\sigma$ of 2.6 and $5.1 \%$ for the original analysis, and 2.4 and $5.0 \%$ for the shifted sounding analysis. Using geometric mean instead of arithmetic mean also yields strong similarity between the two analyses.

Shifting the source level of entrained air upwards decreases the entrainment mass fraction $m_{\mathrm{o}}$. The decrease in $m_{\mathrm{o}}$ is expected, because by effectively entraining air from a higher altitude into the cloud, the energy and water content of the entrained air source decreases, and therefore the clouds need to entrain less air (compared to the normal sounding case) in order to generate the same MSE and $q_{\mathrm{t}}$ decrease from adiabatic cloud values. For 8 September (Fig. 9), mean $m_{\mathrm{o}}$ decreases from 52 to $37 \%$ with the upward-shift in entrainment level. The standard deviation of $m_{\mathrm{o}}$ remains similar, with values of 14 and $12 \%$ respectively. These tests sug- 

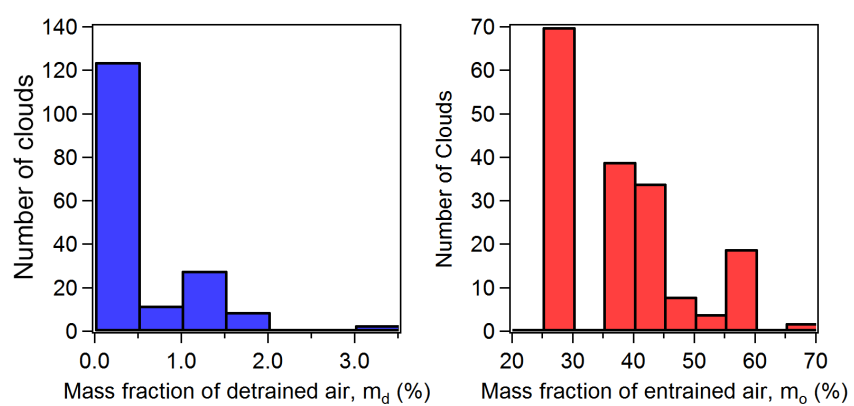

Figure 10. Histograms of detrained (left) and entrained (right) air mass fractions under the assumption that the detrained air has exactly the same properties as the air sampled during the aircraft penetration.

gest that our analysis is robust with respect to our assumption of lateral entrainment. Detrainment mass fractions change rather little, while entrainment mass fractions change moderately in the expected manner.

Another assumption made in this method is that the mixedlayer air comprising the cloud is an unbiased sample. Updrafts, however, are biased towards warmer temperatures so $T_{\mathrm{a}}$ is likely biased slightly low. If we were to use only the top $10 \%$ of temperature values in calculating MSE, the temperature bias estimated from the data is about $0.5 \mathrm{~K}$, which leads to an $s_{\mathrm{a}}$ bias of $0.5 \mathrm{~kJ} \mathrm{~kg}^{-1}$. This is much smaller than the change in MSE caused by shifting the entrainment levels by $400 \mathrm{~m}$, which is around 3 to $4 \mathrm{~kJ} \mathrm{~kg}^{-1}$ depending on the day. Thus, we do not expect the mixed-layer air bias in MSE to substantively change the results.

\subsubsection{Detrained air properties}

The issue of detrainment is made more complex because we only sample each cloud at one level, and therefore we have no information about any single cloud's properties at different altitudes or time (as opposed to entrainment where we have a clear-air sounding that provides information at all altitudes). We have previously assumed that the detrained air has properties that are the average of the sampled cloud and the adiabatic air (Sect. 2.4); see Eqs. (6) and (7). This is rationalized because detrainment from the cloud could have occurred at any time in the past, at which time the cloud would have been closer to adiabatic than at the moment of the aircraft cloud penetration. Here, we change the assumption to one where detrainment occurred when the cloud properties are exactly that at the moment of the penetration, i.e., $q_{\mathrm{d}}=q_{\mathrm{c}}$ and $s_{\mathrm{d}}=s_{\mathrm{c}}$. Figure 10 shows the detrained and entrained air mass fractions when this is assumed. The mean values of $m_{\mathrm{d}}$ are still small, and in fact are smaller than the results shown in Fig. 5. The other difference from the base case detrainment scenario is that the large detrainment events no longer exist; the maximum value of $m_{\mathrm{d}}$ is $3 \%$. Physically, this seems to be less plausible than the results from our base case, but does

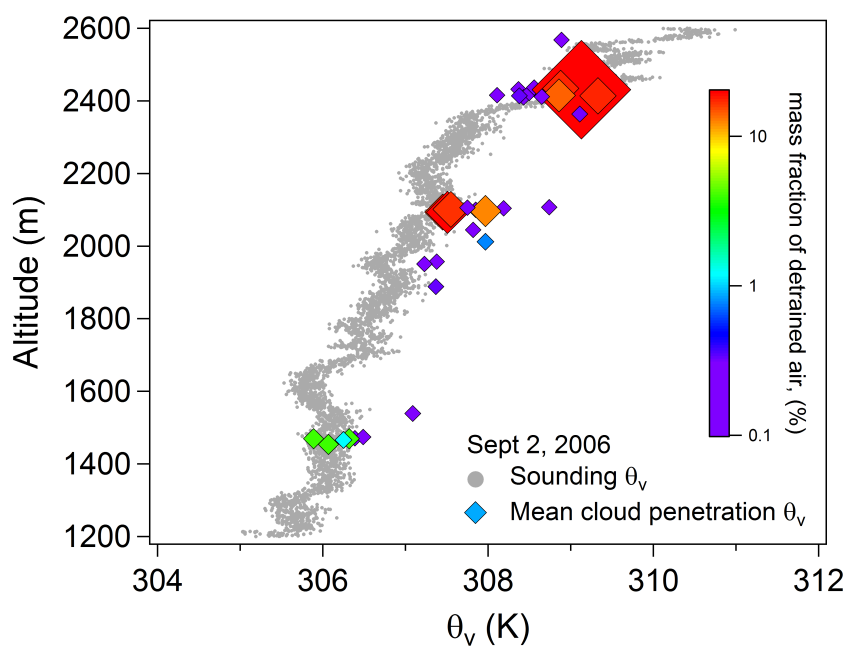

Figure 11. Virtual potential temperature $\theta_{\mathrm{V}}$ of the environmental air (gray dots) from an aircraft sounding and mean $\theta_{\mathrm{V}}$ (colored diamonds) for the air during each cloud penetration on 2 September 2006. The detrainment mass fraction $m_{\mathrm{d}}$ for each penetration is indicated by both color and size of the diamond symbol.

illustrate that the detrainment values deduced by this method exhibit some sensitivity to the assumption of the properties of the detrained air. The corresponding entrainment mass fractions $m_{\mathrm{o}}$ under this assumption are 25 to $60 \%$ as compared to 30 to $70 \%$ in the base case, a small shift that does not change the qualitative picture of the mass fluxes in these clouds. These sensitivity tests show that our results do depend on the assumed detrained air properties, mainly in the fraction of large $m_{\mathrm{d}}$ events, although we consider our base case analysis to be more realistic regarding detrainment than the model used in this sensitivity analysis. The overall picture is consistent between these two analyses: detrainment is generally a weak process in these summertime shallow cumulus clouds.

\section{Relationship with buoyancy profiles}

Previous studies have suggested that detrainment is related to cloud buoyancy profiles. For example, a modeling study by Carpenter et al. (1998b) found that cold descending air will sink until it reaches its level of neutral buoyancy, at which point it will diverge and detrain. Bretherton and Smolarkiewicz (1989) suggest that changes in the gradient of the buoyancy of the cloudy air causes entrainment or detrainment. While our observations can not inform the latter, the former hypothesis can be tested in our observations.

To test these ideas, we compare the environmental density profile along with the measured penetration cloudy air density, both expressed as virtual potential temperature $\theta_{\mathrm{v}}$. Figures 11 and 12 illustrate results for 2 of the 6 days. The detrainment mass fraction $m_{\mathrm{d}}$ for each penetration is indi- 


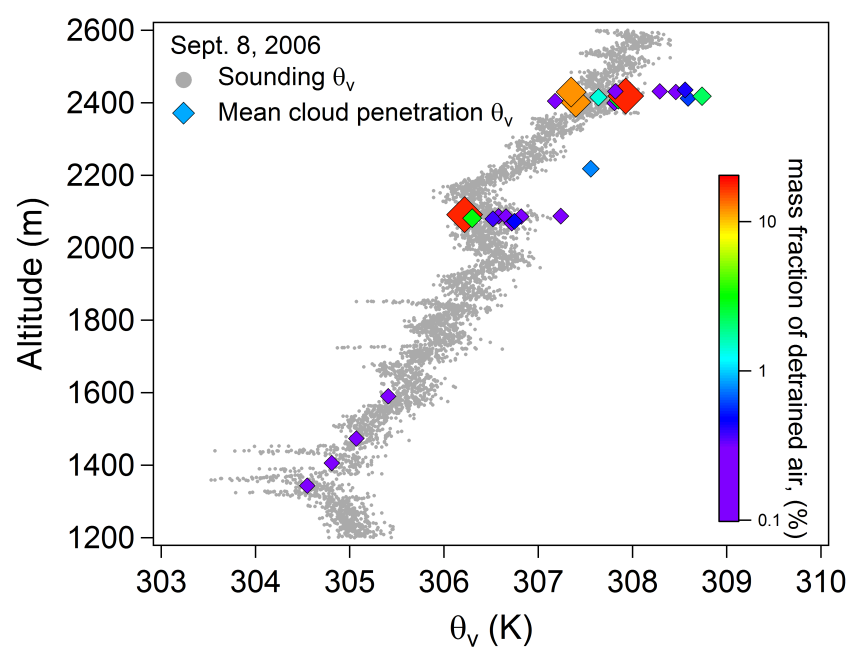

Figure 12. Virtual potential temperature $\theta_{\mathrm{V}}$ of the environmental air (gray dots) from an aircraft sounding and mean $\theta_{\mathrm{V}}$ (colored diamonds) for the air during each cloud penetration on 8 September 2006. The detrainment mass fraction $m_{\mathrm{d}}$ for each penetration is indicated by both color and size of the diamond symbol.

cated by both color and size of the data marker. In general, the results show that the cloudy air either exhibits $\theta_{\mathrm{v}}$ values that are equal to or larger than the environment. This is consistent with the formation of cumulus clouds by air that is positively buoyant relative to the environment. While one expects a shell of cold, negatively buoyant, descending air to be present around the periphery of the cloud, this is offset in the mean by the warm, positively buoyant air inside this shell, at least for actively growing clouds. For those cloud slices that are substantially positively buoyant relative to the environmental sounding, the maximum difference in $\theta_{\mathrm{v}}$ is less than $2 \mathrm{~K}$, with most within $1 \mathrm{~K}$. There are a handful of penetrations where the cloudy air is negatively buoyant relative to the environment; the difference in $\theta_{\mathrm{v}}$ in these cases appears to be smaller than for the positively buoyant cases, though the small sample size makes it difficult to reach any statistically significant conclusion. The small fraction of negatively buoyant penetrations also suggests that sampling is biased against dissipating clouds as speculated above.

If we focus on only those cases with largest $m_{\mathrm{d}}$ values $\left(m_{\mathrm{d}}>10 \%\right)$, we find that almost all of these cloud penetrations (20 out of 22 cases) exhibit mean $\theta_{\mathrm{v}}$ values that are (within uncertainty) the same as the environmental $\theta_{\mathrm{v}}$, i.e., the cloudy air is, on average, at its level of neutral buoyancy. This finding is consistent with the hypothesis of detrainment occurring at the level of neutral buoyancy (Carpenter et al., 1998b). There are two counter-examples over all 6 days; one of these is illustrated in Fig. 11 (near $2100 \mathrm{~m}$ altitude and $\theta_{\mathrm{v}}=308 \mathrm{~K}$ ) where the cloudy air is warmer by $\sim 0.5 \mathrm{~K}$. In contrast, the fraction of events at low $m_{\mathrm{d}}$ which exhibit $\theta_{\mathrm{v}}$ values that are substantially warmer than the sounding is much greater, perhaps indicating younger, growing clouds which have detrained very little air over their history. At these low $m_{\mathrm{d}}$ values, though, the most likely case is still one where the cloudy air $\theta_{\mathrm{v}}$ very closely matches the environment.

Lastly, we also see no obvious trend of large $m_{\mathrm{d}}$ events correlated to any change in shape of the environmental sounding. If we had, it may have been an indication that the mechanism proposed by Bretherton and Smolarkiewicz (1989) is relevant to these observations; the lack of such a correlation, though, neither proves nor disproves this mechanism as we have no vertical profiles of in-cloud buoyancy to properly test it.

\section{Conclusions}

We have proposed a novel method to estimate the amounts of gross detrainment and entrainment using aircraft observations. The method optimizes conservation equations for cloud mass, moist static energy and total moisture to solve for the mass fractions of adiabatic, entrained and detrained air (termed $m_{\mathrm{a}}, m_{\mathrm{o}}$, and $m_{\mathrm{d}}$ respectively) for each aircraft cloud penetration. In warm, shallow, non-precipitating cumuli, we find that these clouds are comprised of approximately equal parts of surface-layer air that has been lifted adiabatically and entrained air, the latter comprising between 30 and $70 \%$ of the cloud mass, with a median of $45 \%$. Detrainment mass fractions are found to be typically quite low, with $78 \%$ of our cases exhibiting $m_{\mathrm{d}}<2 \%$. In about $15 \%$ of our aircraft cloud penetrations, however, we estimate $m_{\mathrm{d}}>10 \%$. These low values may be inconsistent with budget studies in towering and/or congestus cumuli, which infer detrainment mass fluxes comparable to the upward mass flux of surfacelayer air (Raymond and Wilkening, 1982, 1985; Raga et al., 1990; Barnes et al., 1996; Carpenter et al., 1998a). These results are more consistent with those from Wang and Geerts (2011), who find no evidence of active detrainment; their study, along with this one, suggests that vertical transport is dominated by the air that remains after dissipation of the cloud, with little active detrainment to the environment during the cloud's active phase. The incompatibility of these results with other previous studies could be explained if detrainment fluxes in cumulus clouds are controlled by parameters that differ among these studies. Such controlling parameters might include cloud type (e.g., cumulus mediocris vs. congestus) and surrounding dynamic and thermodynamic environmental properties (e.g., subsidence rate; $T$ and humidity profiles). Differences in study methodology may also play a role, of which we highlight a few: uncertainties in mass budgets; possible biases in our aircraft sampling towards younger, more vigorous clouds; detrainment occurring at specific layers that are not easily sampled by aircraft; and strong variability of detrainment with cloud height or cloud age.

Vertical profiles of detrainment show a trend of increasing $m_{\mathrm{d}}$ with height in the cloud, consistent with Raga et al. 
(1990). Vertical profiles of entrainment also show an increase in the upper-half of the cloud as compared to the lower-half, which fits with the common observation that adiabaticity in cumulus tends to decrease with height (e.g., Lu et al., 2008). Our confidence in our new method is increased because the inferred vertical trends are physically sensible.

We also find that more than $90 \%$ of the larger detrainment events $\left(m_{\mathrm{d}}>10 \%\right)$ is associated with cloudy air that has $\theta_{\mathrm{v}}$ equal to that of the environmental sounding. This is consistent with Carpenter et al. (1998b) that found that descending air will detrain when it reaches its level of neutral buoyancy. In contrast, clouds with low $m_{\mathrm{d}}$ were much more frequently associated with air that was positively buoyant relative to the environment.

A number of assumptions were made as part of this analysis. Most notably, we assume that entrainment occurs laterally at the level of observation, and that detrained air has properties that are the average of adiabatic air and the air sampled by the aircraft. Sensitivity tests show that the former does not dramatically change the qualitative results of this study. Changing the latter assumption to one where detrained air has exactly the same properties as the cloudy air at the same sampling level causes all the detrainment events to shift to small $(<2 \%)$ values. Testing this methodology in high resolution models is an important future step to gain further confidence in these results.

Compared to entrainment, detrainment is far less-studied despite its importance to understanding clouds, its role in atmospheric transport, and, consequently, weather and climate. The dearth of previous studies of gross detrainment hampers our ability to evaluate these results within a broader context, especially when we expect detrainment to depend on cloud type and environmental conditions. Developing a deeper understanding of detrainment from clouds, and its controlling parameters, will likely require combining a variety of approaches, of which this study is one example, in a variety of settings.

Acknowledgements. The authors thank NOAA for funding participation in the GoMACCS aerosol-cloud field experiment, and the Physical Meteorology program of the National Science Foundation (AGS-1139746) for supporting publication of this manuscript. We also thank the CIRPAS Twin Otter team for all their dedicated work to make this field program a great success. We are indebted to John Seinfeld and Rick Flagan for their scientific leadership during this experiment, and the rest of the Twin Otter science team for various discussions along the way.

Edited by: G. Vaughan

\section{References}

Barnes, G. M., Fankhauser, J. C., and Browning, W. D.: Evolution of the vertical mass flux and diagnosed net lateral mixing in isolated convective clouds, Mon. Weather Rev., 124, 2764-2784, 1996.

Blyth, A. M.: Entrainment in cumulus clouds, J. Appl. Meteor., 32, 626-641, 1993.

Blyth, A. M., Lasher-Trapp, S. G., and Cooper, W. A.: A study of thermals in cumulus clouds, Q. J. Roy. Meteorol. Soc., 131, 1171-1190, 2005.

Bretherton, C. S. and Smolarkiewicz, P. K.: Gravity-waves, compensating subsidence and detrainment around cumulus clouds, J. Atmos. Sci., 46, 740-759, 1989.

Carpenter, R., Droegemeier, K., and Blyth, A.: Entrainment and detrainment in numerically simulated cumulus congestus clouds. Part II: Cloud budgets, J. Atmos. Sci., 55, 3433-3439, 1998a.

Carpenter, R. L., Droegemeier, K. K., and Blyth, A. M.: Entrainment and detrainment in numerically simulated cumulus congestus clouds. Part III: Parcel analysis, J. Atmos. Sci., 55, 34403455, 1998 b.

Chand, D., Wood, R., Anderson, T. L., Satheesh, S. K., and Charlson, R. J.: Satellite-derived direct radiative effect of aerosols dependent on cloud cover, Nat. Geosci., 2, 181-184, doi:10.1038/ngeo437, 2009.

Damiani, R. and Vali, G.: Evidence for tilted toroidal circulations in cumulus, J. Atmos. Sci., 64, 2045-2060, doi:10.1175/JAS3941.1, 2007.

Dawe, J. T. and Austin, P. H.: The influence of the cloud shell on tracer budget measurements of LES cloud entrainment, J. Atmos. Sci., 68, 2909-2920, doi:10.1175/2011JAS3658.1, 2011.

de Rooy, W. C., Bechtold, P., Froehlich, K., Hohenegger, C., Jonker, H., Mironov, D., Siebesma, A. P., Teixeira, J., and Yano, J.-I.: Entrainment and detrainment in cumulus convection: an overview, Q. J. R. Meteorol. Soc., 139, 1-19, doi:10.1002/qj.1959, 2013.

de Rooy, W. C. and Siebesma, A. P.: Analytical expressions for entrainment and detrainment in cumulus convection, Q. J. Roy. Meteorol. Soc., 136, 1216-1227, doi:10.1002/qj.640, 2010.

Gerber, H., Arends, B. G., and Ackerman, A. S.: New microphysics sensor for aircraft use, Atmos. Res., 31, 235-252, 1994.

Heus, T., Van Dijk, G., Jonker, H. J. J., and Van den Akker, H.: Mixing in shallow cumulus clouds studied by Lagrangian particle tracking, J. Atmos. Sci., 65, 2581-2597, doi:10.1175/2008JAS2572.1, 2008.

Hoffmann, F., Siebert, H., Schumacher, J., Riechelmann, T., Katzwinkel, J., Kumar, B., Goetzfried, P., and Raasch, S.: Entrainment and mixing at the interface of shallow cumulus clouds: Results from a combination of observations and simulations, Meteorol. Z., 23, 349-368, 2014.

Houghton, H. G. and Cramer, H. E.: A theory of entrainment in convective currents, J. Meteor., 8, 95-102, 1951.

Kitchen, M. and Caughey, S. J.: Tethered-balloon observations of the structure of small cumulus clouds, Q. J. Roy. Meteorol. Soc., 107, 853-874, 1981.

Lawson, R. P. and Cooper, W. A.: Performance of some airborne thermometers in clouds, J. Atmos. Oceanic Technol., 7, 480-494, 1990.

Liao, H. and Seinfeld, J. H.: Effect of clouds on direct aerosol radiative forcing of climate, J. Geophys. Res., 103, 3781-3788, doi:10.1029/97JD03455, 1998. 
Lu, M. L., Feingold, G., Jonsson, H. H., Chuang, P. Y., Gates, H., Flagan, R. C., and Seinfeld, J. H.: Aerosol-cloud relationships in continental shallow cumulus, J. Geophys. Res. Atmos., 113, D15201, doi:10.1029/2007JD009354, 2008.

Malkus, J. S.: Some results of a trade-cumulus cloud investigation, J. Meteor., 11, 220-237, 1954.

Perry, K. D. and Hobbs, P. V.: Influences of isolated cumulus clouds on the humidity of their surroundings, J. Atmos. Sci., 53, 159174, 1996.

Raga, G. B., Jensen, J. B., and Baker, M. B.: Characteristics of cumulus band clouds off the coast of Hawaii, J. Atmos. Sci., 47, 338-355, 1990.

Raymond, D. J. and Wilkening, M.: Characteristics of mountaininduced thunderstorms and cumulus congestus clouds from budget measurements, J. Atmos. Sci., 42, 773-783, 1985.

Raymond, D. J. and Wilkening, M. H.: Flow and mixing in New Mexico mountain cumuli, J. Atmos. Sci., 39, 2211-2228, 1982.

Raymond, D. J., Solomon, R., and Blyth, A. M.: Mass fluxes in New Mexico mountain thunderstorms from radar and aircraft measurements, Q. J. Roy. Meteorol. Soc., 117, 587-621, doi:10.1002/qj.49711749909, 1991.

Rougier, J., Sexton, D. M. H., Murphy, J. M., and Stainforth, D.: Analyzing the climate sensitivity of the HadSM3 climate model using ensembles from different but related experiments, J. Climate, 22, 3540-3557, doi:10.1175/2008JCLI2533.1, 2009.
Samset, B. H. and Myhre, G.: Vertical dependence of black carbon, sulphate and biomass burning aerosol radiative forcing, Geophys. Res. Lett., 38, L24802, doi:10.1029/2011GL049697, 2011.

Small, J. D., Chuang, P. Y., Feingold, G., and Jiang, H. L.: Can aerosol decrease cloud lifetime?, Geophys. Res. Lett., 36, L16806, doi:10.1029/2009GL038888, 2009.

Stith, J. L.: Observations of cloud-top entrainment in cumuli, J. Atmos. Sci., 49, 1334-1347, 1992.

Taylor, G. R. and Baker, M. B.: Entrainment and detrainment in cumulus clouds, J. Atmos. Sci., 48, 112-121, 1991.

Wang, Y. and Geerts, B.: Observations of detrainment signatures from non-precipitating orographic cumulus clouds, Atmos. Res. 99, 302-324, doi:10.1016/j.atmosres.2010.10.023, 2011.

Wang, Y., Geerts, B., and French, J.: Dynamics of the cumulus cloud margin: An observational study, J. Atmos. Sci., 66, 36603677,doi:10.1175/2009JAS3129.1, 2009.

Yeo, K. and Romps, D.: Measurement of Convective Entrainment Using Lagrangian Particles, J. Atmos. Sci., 70, 266-277, doi:10.1175/JAS-D-12-0144.1, 2013.

Zhao, M. and Austin, P. H.: Life cycle of numerically simulated shallow cumulus clouds. Part II. Mixing dynamics, J. Atmos. Sci., 62, 1291-1310, doi:10.1175/JAS3415.1, 2005. 